\title{
POLIMORFISMO DE LOS MARCADORES MICROSATÉLITES D7S820 Y D16S539 EN UNA MUESTRA DE POBLADORES DE LA PROVINCIA DE YUNGAY, DEPARTAMENTO DE ANCASH"
}

\section{ABSTRACT}

\author{
Rolando Martinez ${ }^{\mathrm{a}}$ Susan Polo ${ }^{\mathrm{a}}$, Raúl Tito ${ }^{\mathrm{b}}$ y Beatriz Lizárraga ${ }^{\mathrm{a}}$
}

Recently, STR (Short Tandem Repeat) molecular markers have caused a revolution in the field of Population Genetics and Forensic Genetics due to its high index of probability in the identification of individuals, paternity and family relationships. Nevertheless, the problematic of the identification of human beings with DNA examinations in Peru is limited by the scanty investigation on the determination of allelic frequencies of Peruvian populations. Here we present the result of the genetic variability of microsatellites D7S820 and D16S539 in a population sample of 35 people from the province of Yungay, state of Ancash. The alleles reported here are 9, 10, 11, 12 and 14 for the marker D7S820 and 9, 10, 11, 12 and 13 for the marker D16S539; we found both markers are in genetic balance (Hardy and Weinberg) population sample. There is no significant difference of the allelic frequencies of the sample in study with regard to a population representative sample of Peru for these two markers. In the population analysis, sample from Yungay has more relation with samples from Asian origin; the results corroborate the Asian influence of Native American population.

Keys words: STRs, Yungay, equilibrium genetic, analysis population.

\section{INTRODUCCIÓN.}

Los STR's, corresponden a un pequeño, pero muy importante grupo de marcadores moleculares disponibles hasta la fecha, conocidos también como microsatélites estos se encuentran esparcidos en todo el genoma , corresponden a fragmentos de dos a seis nucleótidos repetidos varias veces uno a continuación de otro, presentan alto polimorfismo, sirven para la identificación de individuos en biología forense y también para la estimación de parámetros de heterozigosidad, homozigocidad, diversidad biológica, evolución molecular y mapeo genético (Cerda et al., 2002) en investigaciones que involucran a poblaciones mestizas y poblaciones aborígenes, las cuales son comparadas con datos de poblaciones ya estudiadas para entender los patrones de poblamiento e Historia Genética (por ejemplo: poblamiento de América), apoyándose también en datos lingüísticos, morfológicos, geográficos y arqueológicos ( Lewis et al., 2004).

\section{METODOLOGÍA.}

Se obtuvo células de epitelio bucal, mediante un raspado con un hisopo estéril, de 35 pobladores no emparentados de la provincia de Yungay, departamento de Ancash Perú, los cuales fueron colocados en tubos de $1.5 \mathrm{ml}$ que contenían $100 \mu \mathrm{l}$ de buffer de lisis $(10 \mathrm{mM}$ Tris $\mathrm{HCl} \mathrm{pH} 8$, $25 \mathrm{mM}$ EDTA, $100 \mathrm{mM} \mathrm{NaCl}, 0,5 \%$ SDS), luego fueron transportados a la ciudad de Lima, en un empaque adecuado y a temperatura ambiente $\left(20^{\circ}\right)$ para su posterior almacenamiento a $-20^{\circ} \mathrm{C}$.

Para la extracción de ADN se utilizó el procedimiento simplificado sin fenol. Finalmente se resuspendió la muestra en $200 \mu \mathrm{l}$ de buffer y se almacenó a $-20^{\circ} \mathrm{C}$ para su conservación. Se realizó una amplificación simultánea para los microsatélites D7S820 y D16S539 (Murray et al., 1995).La separación de los amplicones se obtuvo por electroforesis en geles de Poliacrilamida al 6\% Úrea 7M. Los geles fueron teñidos con Nitrato de Plata. Para el análisis de datos se uso los programas: Power Stats
(Teresa., 1999), GDA, Arlequín y MEGA (Kumar et al., 2001

\section{DISCUSIÓN}

La prueba exacta de diferenciación poblacional esta basado en el principio de que en una población los alelos presentes en los marcadores trabajados están distribuidos al azar y esta misma distribución al ser comparada en otra población es la misma y por lo tanto no existen diferencias. Los resultados fueron de: $0.48835 \pm 0.01980$ para el marcador D7S820 y $0.17320 \pm 0.01552$ para el D16S820 a un nivel de significancia de 0.05 . Esto nos indica que los valores no son significativos y por lo tanto se acepta la hipótesis de que no existen diferencias significativas entre la muestra poblacional de la provincia de Yungay y la muestra de la población general de Perú; por lo tanto existe homogeneidad genética entre estas dos muestras.

A pesar de que al comparar la muestra poblacional de la provincia de Yungay con la muestra representativa de la población peruana (Tito et al., 2004) no encontramos en la primera los alelos 7,8 y 13 para el marcador microsatélite D7S820 y los alelos 8 y 14 para el D16S539, no existen diferencias significativas al aplicar el test de diferenciación poblacional entre ambas poblaciones esto es debido a que los alelos que no están presentes en la muestra poblacional de la provincia de Yungay se encuentran en muy baja frecuencia en la muestra poblacional general de Perú, es por esto que no afectan en el resultado final.

La matriz de Reynolds obtenida al comparar las frecuencias de las 3 poblaciones oriundas del Perú (Tupe, Nomatsigenga, Ancash) más la muestra poblacional de la provincia de Yungay fue sometida al algoritmo del método Neighbor-Joining cuyo principio es la unión de unidades taxonómicas (OTU's) mas cercanos tratando de minimizar la longitud total del árbol y la no utilización de tasas de evolución constantes entre OTU's. Obteniéndose un árbol del tipo UnRooted donde se puede

\footnotetext{
Laboratorio de Biología Molecular y Ácidos Nucleicos, Centro de Investigación de Bioquímica y Nutrición, Facultad de Medicina Humana-UNMSM.

${ }^{\mathrm{b}}$ Molecular Evolutionary Genetics - Biodesign Institute- Arizona State University
} 
apreciar que la muestra de Yungay y Ancash (muestra departamental) se encuentran mas cercanamente relacionadas (Figura $\mathrm{N}^{\circ} 1$ ). Esto es debido a que ambas muestras corresponden a zonas geográficas contiguas y están influenciadas mutuamente. La baja influencia andina que poseen las tribus selváticas, hace que la muestra poblacional de Nomatsigenga se encuentre alejada de las tres poblaciones andinas.

En los árboles filogenéticos de ambos marcadores generados con respecto a muestras poblacionales mundiales se puede apreciar la gran influencia que tienen las poblaciones de origen asiático sobre la muestra poblacional de Yungay, aceptándose que el estrecho de Bering fue el paso hacia América de estas poblaciones asiáticas y corroborándose con investigaciones en los campos lingüísticos, antropomórficos, genéticos y culturales ( Lewis et al., 2004).. Así también con respecto a poblaciones de origen hispano, se observa que para el marcador D7S820 las muestras hispanas poseen alta cercanía con respecto a la población en estudio, esto es ya conocido por datos históricos de que la cultura hispana formó una colonia en América del Sur influenciando cultural, histórico y genéticamente sobre las poblaciones de los andes como la de Yungay. Para el caso de las poblaciones africanas se observa poca cercanía genética con respecto a la muestra poblacional de Yungay; esto es debido a la nula influencia africana sobre las poblaciones andinas a pesar que en la época de la colonia hubo una gran migración de pobladores africanos traídos como esclavos al Perú, pero éstos se establecieron a lo largo de la costa peruana, mas no en la serranía.

\section{RESULTADOS}

\begin{tabular}{|l|l|l|}
\hline ALELOS & D7S820 & D16S539 \\
\hline 7 & - & - \\
\hline 8 & - & - \\
\hline 9 & 0.0143 & 0.4 \\
\hline 10 & 0.2847 & 0.1714 \\
\hline 11 & 0.5 & 0.1 \\
\hline 12 & 0.1857 & 0.2857 \\
\hline 13 & - & 0.0429 \\
\hline 14 & 0.0143 & - \\
\hline 15 & - & - \\
\hline PIC & 0.5695 & 0.6704 \\
\hline PD & 0.7771 & 0.8376 \\
\hline He & 0.7143 & 0.8286 \\
\hline HW $(\mathrm{F})$ & 0.69 & 0.201 \\
\hline HW $(\chi)$ & 0.7165 & 0.1675 \\
\hline DP & $0.48835 \pm 0.01980$ & $0.17320 \pm$ \\
& & 0.01552 \\
\hline h & 0.65211 & 0.73825 \\
\hline
\end{tabular}

\section{CONCLUSIONES.}

Se reportan 5 alelos $(9,10,11,12$ y 14) para el marcador microsatélite D7S820 y también 5 alelos $(9,10,11,12$ y 13) para el marcador D16S539 en la muestra poblacional de la provincia de Yungay.

La muestra poblacional de la provincia de Yungay se encuentra en equilibrio genético o equilibrio de Hardy Weinberg para estos dos marcadores microsatélites.
Las frecuencias de los alelos reportados para estos dos marcadores microsatélites, no tiene diferencia significativa con respecto a las frecuencias de estos dos mismos marcadores microsatélites en una muestra poblacional representativa de Perú (Tito et al., 2004).

Se observa una heterozigosidad superior al $70 \%$ en ambos marcadores microsatélites en la muestra poblacional de la provincia de Yungay, comportándose igual que la gran mayoría de poblaciones mundiales estudiadas hasta la fecha.

El valor de diversidad genética encontrado para ambos marcadores microsatélites se encuentra dentro del promedio para poblaciones amerindias.

El árbol filogenético generado de las 3 poblaciones de origen peruano con la muestra poblacional de Yungay (Figura $\mathrm{N}^{\circ} 01$ ), indica de que esta ultima tiene más relación con la población de Ancash para ambos marcadores microsatélites y que la población de Nomatsigenga presenta poca relación con la muestra en estudio.

Los árboles filogenéticos generados tanto para muestras amerindias como para muestras mundiales (Figura $\mathrm{N}^{\circ}$ 02) para ambos marcadores corroboran la influencia de los grupos asiáticos sobre poblaciones amerindias (Budowle et al., 2001).

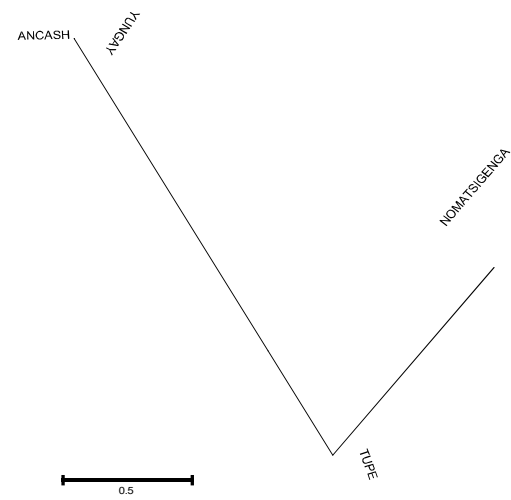

Figura $\mathrm{N}^{\circ}$ 1.-Árbol Filogenético OnRooted que utiliza el principio de Neighbor-Joining (Nei, 2001). Generado a partir de la frecuencias alélicas de ambos marcadores de tres poblaciones aborígenes de Perú (Tupe, Ancash y Nomatsigenga) y la muestra de Yungay

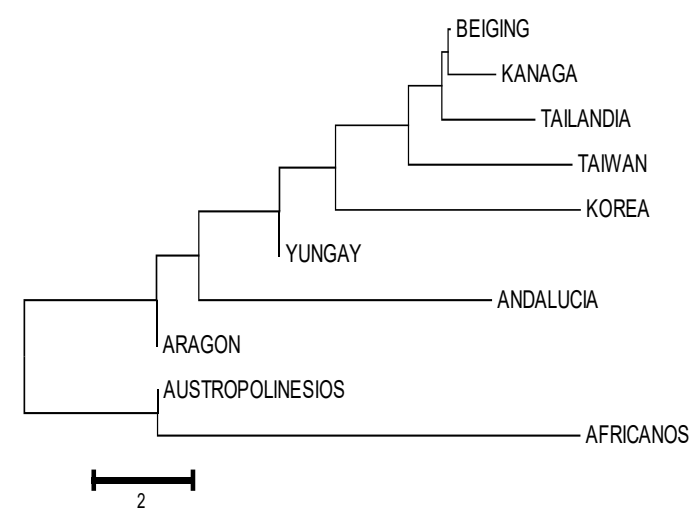

Figura $\mathrm{N}^{\circ}$ 2. Árbol Filogenético que utiliza el principio de NeighborJoining (Nei, 2001) generado a partir de las frecuencias alélicas de marcador D7S820 para 9 poblaciones mundiales mas la muestra poblacional de Yungay 


\section{REFERENCIAS BIBLIOGRAFICAS}

[1]. Budowle, B., Shea, B., Niezgoda, S., and Chakraborty, R.CODIS STR loci data from 41 sample populations. J Forensic Sci. 2001.46:453-489.

[2]. Cerda, R., Bruce B., and Li J., .Maximun likelihood estimates of admixture in northeastem Mexico using 13 short tandem repeat loci. Am J Hum Genet. 2002. 14:429-439

[3]. Fisher. R., Standar calculation for evaluating a blood-group system. Heredity. 1951. 5: 95-102.

[4]. Kumar, S., Tamura, K and Nei, M. MEGA 2: Molecular Evolutionary Genetics Analysis Software. 2001. Arizona State University. USA.

[5]. Lewis, C., Tito, R., Lizárraga, B. Stone, A., Language, and Loci: MtDNA in Native Americans and the Genetic History of Perú. American Journal of Physical Anthropology. In press 2004.

[6]. Murray, J., Sheffield, V., Weber, J., and Duyk, G. Human STS sequence tagged site. Cooperative Human Linkage Center.Unpublished. 1995.

http://www.ncbi.nlm.nih.gov/entrez/query.fcgicmd=retrieve.nucleotide/genbak.

[7]. Nei, M., and Kumar, S. Molecular evolution and phylogenetics. 2001. Oxford University Press.

[8]. Tereba, A. Tools for analysis of population statistics, in: Profiles in ADN, Promega Corporation, 1999. 2: 14-16.

[9]. Tito, R., Lopez, P., lannacone, G., and Lizárraga, B. Genetic diversity of sixteen STRs in the Peruvian Mesa Redonda Lima population. Journal of Forensic Science. 2004. 49: 852-853. 